\title{
Decentralized surgery of abdominal wall defects in Germany
}

\author{
Andrea Schmedding ${ }^{1}\left(\mathbb{D} \cdot\right.$ Boris Wittekind $^{2} \cdot$ Emilia Salzmann-Manrique $^{3} \cdot$ Rolf Schloesser $^{2} \cdot$ Udo Rolle $^{1}$
}

Accepted: 5 March 2020 / Published online: 26 March 2020

(c) The Author(s) 2020

\begin{abstract}
Purpose Neonatal surgery for abdominal wall defects is not performed in a centralized manner in Germany. The aim of this study was to investigate whether treatment for abdominal wall defects in Germany is equally effective compared to international results despite the decentralized care.

Methods All newborn patients who were clients of the major statutory health insurance company in Germany between 2009 and 2013 and who had a diagnosis of gastroschisis or omphalocele were included. Mortality during the first year of life was analysed.

Results The 316 patients with gastroschisis were classified as simple (82\%) or complex (18\%) cases. The main associated anomalies in the 197 patients with omphalocele were trisomy 18/21 (8\%), cardiac anomalies (32\%) and anomalies of the urinary tract (10\%). Overall mortality was $4 \%$ for gastroschisis and $16 \%$ for omphalocele. Significant factors for non-survival were birth weight below $1500 \mathrm{~g}$ for both groups, complex gastroschisis, volvulus and anomalies of the blood supply to the intestine in gastroschisis, and female gender, trisomy 18/21 and lung hypoplasia in omphalocele.

Conclusions Despite the fact that paediatric surgical care is organized in a decentralized manner in Germany, the mortality rates for gastroschisis and omphalocele are equal to those reported in international data.
\end{abstract}

Keywords Gastroschisis $\cdot$ Omphalocele $\cdot$ Neonatal surgery outcome $\cdot$ Child $\cdot$ Mortality

\section{Introduction}

Gastroschisis and omphalocele are rare diseases, but are the most common abdominal wall defects. The prevalence of gastroschisis is $4-5$ per 10,000 births, and that of omphalocele is 2 per 10,000 births [1,2]. Gastroschisis is an abdominal wall defect in which the abdominal organs eviscerate through an opening in the abdominal wall that is usually located on the right side of the umbilicus [3, 4]. The malformation can be classified as complex, defined by the presence of intestinal atresia, perforation, necrotic segments,

Andrea Schmedding

andrea.schmedding@kgu.de

1 Department of Pediatric Surgery and Pediatric Urology, University Hospital, Goethe University Frankfurt, Theodor-Stern-Kai 7, 60590 Frankfurt am Main, Germany

2 Department of Neonatology, University Hospital, Goethe University Frankfurt, Theodor-Stern-Kai 7, 60590 Frankfurt am Main, Germany

3 Department of Pediatric Stem Cell Transplantation, University Hospital, Goethe University Frankfurt, Theodor-Stern-Kai 7, 60590 Frankfurt am Main, Germany or volvulus, or as simple; the category of the defect has an impact on the outcome [5]. With omphalocele, herniation of organs into the umbilical cord occurs. Infants with omphalocele usually present with a hernia sac. Omphalocele is more often accompanied by associated anomalies, especially chromosomal anomalies [3, 4].

Abdominal wall defects are usually detected using prenatal ultrasound $[6,7]$. This allows prenatal referral to a centre with experience in paediatric surgery, neonatology and specialized obstetrics for most women. In Germany in 2005 , the joint federal committee (G-BA) decided on regulations regarding the quality of care for preterm and newborn babies in perinatal centres. These regulations divided prenatal care into levels; level one indicates the highest level of care, which means the care of neonates born at less than 29 weeks of gestation or birth weight less than 1250 g. For these units, it is necessary to have regulated access to paediatric surgery [8]. In keeping with the growing number of level 1 units after 2005, the number of paediatric surgical units increased as well. As the number of births and the number of children with congenital malformations did not increase in parallel, we now have a system that includes 
small specialized neonatal units [9] and a small caseload for congenital malformations, as could be shown for the year 2015 , in which 89 departments of paediatric surgery treated $93 \%$ of the abdominal wall defects with an average case load of less than five cases per unit [10].

Because of the historical development towards decentralization of paediatric surgery in Germany, the question arose whether the outcome of congenital wall defects in Germany is equal to the outcomes reported in international results. In Germany, no clinical national registries exist for these congenital deformities.

A hospital treatment leads to a dataset that is provided to the health insurance companies for accounting purposes; this dataset includes diagnoses and procedures. Data of this type have been used in the analysis of clinical questions [11]. The dataset of the largest health insurance company was used for the analysis of the treatment and outcome of abdominal wall defects.

\section{Methods}

The database of the major health insurance company in Germany (Allgemeine Ortskrankenkasse, AOK) was retrospectively analysed for the years 2009-2013. This database is produced for accounting purposes according to $\S 301$ of the German social security code V. It contains personal and medical data of the patients. It includes codes for diagnoses based on the International Statistical Classification of Diseases and Related Health Problems-German modification (ICD-10-GM) [12] and codes for procedures based on the German procedure classification (OPS) [13]. For each medical dataset one main diagnosis, up to 20 secondary diagnoses and 99 procedures can be submitted from the hospitals to the insurance company [14].

In Germany in $2011,87 \%$ of the inhabitants were insured under statutory health insurance (SHI) $[15,16]$. The AOK is the largest statutory health insurance company in the country; it has branches all over the country and covers approximately one-third of German patients. Regarding the socioeconomic status of the clients of AOK, the microcensus of Germany conducted in 2011 (Table 1) shows that the percentage of jobless persons and others who are not working (e.g. children, retired persons) is slightly higher among the insured persons of AOK than among people insured through other insurance companies [17]. Additional factors regarding the socioeconomic status of the insured people were analysed in 2012, and they also indicated a lower socioeconomic status of insured people at AOK [18]. This must be taken into consideration when analysing the data obtained from AOK.

The sample size estimation was made using the statistics for live births in Germany [19]. Taking the number of live births in Germany as 670,000, the prevalence of gastroschisis as 4:10,000 and that of omphalocele as 2:10,000, the expected number of patients with gastroschisis $(\mathrm{G})$ was 268 per year, and the expected number of patients with omphalocele $(\mathrm{O})$ was 134 per year. This would lead to $89(\mathrm{G})$ and $45(\mathrm{O})$ patients in the AOK database per year. Therefore, an analysis of five consecutive years was made.

All newborn patients who were clients of AOK between 2009 and 2013 with a diagnosis of gastroschisis or omphalocele at first admission to the hospital were identified by the ICD-10 codes Q79.3 for gastroschisis and Q79.2 for omphalocele either as the main code or as a secondary code. The full sample of data was used; no patients were withdrawn from the study.

For each patient, the following parameters were obtained and analysed: year of admission, level of perinatal centre, paediatric surgery at the perinatal centre, target diagnosis, gender, birth weight less than $1500 \mathrm{~g}$, length of primary hospital stay, alive at age of 30 days, 3 months, 6 months and 12 months, and secondary diagnoses (K55: abnormalities of vascular supply of intestine, K56.2: volvulus, Q41: atresia of small bowel, Q42: atresia of colon, Q20-24: cardiac anomalies, Q60-64: anomalies of urinary tract, Q76: anomalies of spine or thorax, Q79.0: diaphragmatic hernia, Q33.6: lung hypoplasia, Q90-91: trisomy 18 or 21). The following procedures (OPS) were documented if performed: 5-537, closure of congenital defects of abdominal wall; and 5-431, gastrostomy. The birth weight, which is a mandatory parameter required by the insurance companies, was either taken from the ICD Code P07.00-P07.11 (birthweight less than $1500 \mathrm{~g}$ ) and/or the weight itself. Data for follow-up were obtained at 3 months, 6 months and 12 months and included the parameters of survival and the number of new hospital admissions.
Table 1 Employment status and age under 15 years for people with health insurance

\begin{tabular}{lllll}
\hline 2011 microcensus of Germany & Employed & Jobless & $\begin{array}{l}\text { Not working (e.g. } \\
\text { children, retired) }\end{array}$ & $\begin{array}{l}\text { Age less } \\
\text { than } \\
15 \text { years }\end{array}$ \\
\hline All people with health insurance & $52 \%$ & $3 \%$ & $48 \%$ & $13 \%$ \\
All people in statutory health insurance & $48 \%$ & $3 \%$ & $49 \%$ & $13 \%$ \\
AOK & $41 \%$ & $5 \%$ & $54 \%$ & $13 \%$ \\
\hline
\end{tabular}


For further analysis, a detailed list of the 50 most frequent diagnoses and procedures coded for these patients was also compiled.

\section{Statistical methods}

Descriptive statistics are presented as frequencies and percentages or median with quartiles and range for categorical and continuous variables, respectively. Categorical variables were compared using Fisher's exact test or the Chi-square test.

For the analysis of the length of hospital stay (LOS), we used the nonparametric cumulative incidence function of Fine and Gray [20]. The cumulative incidences of LOS for patients who were discharged to home were performed treating the in-house mortality as a competing risk [21].

In our data, the precise time of death after discharge is unknown. However, all alive patients were followed up for longer than 12 months after discharge, and the status of all patients (alive, died) is known at this time point. Therefore, we used logistic regression to identify variables associated with death from birth to 1 year later. To assess the impact of the variables, odds ratios (ORs) with $95 \%$ confidence intervals (95\% CI) were calculated. Multivariate analysis was not possible for the gastroschisis cohort due to the low number of non-survivors. We adjusted the odds ratio considering the variables sex, birth weight, cardiac anomalies, lung hypoplasia and trisomy $18 / 21$ in the omphalocele patients group.

All tests were two-sided, and a $P$ value $<0.05$ was considered statistically significant. Analyses were performed using $\mathrm{R}$ statistical software version 3.5.3 [22].

\section{Results}

We identified 513 patients, 316 with gastroschisis (G) and 197 with omphalocele (O). All, but 12 patients with gastroschisis (96\%) and all but 3 patients with omphalocele (98\%) were treated at perinatal centres providing paediatric surgical treatment or separate paediatric surgical departments. Gender was documented in all but two patients with gastroschisis and in all but four patients with omphalocele. The male:female ratio was 53:47\% in gastroschisis and 58:42\% in omphalocele. The distribution of the patients, which was rather consistent over the 5 -year period, is shown in Table 2.

Associated anomalies are documented in Table 3. Complex gastroschisis was defined as gastroschisis together with atresia of the small bowel (Q41), atresia of the colon (Q42), volvulus (K56.2), or problems with the vascular supply to the intestine (K55) according to Arnold [4]. Perforation and necrotic segments were not indicated in the dataset. The latter was assumed when the diagnosis of abnormal vascular blood supply was documented. Complex gastroschisis was
Table 2 Distribution of diseases over the 5-year period

\begin{tabular}{lrllll}
\hline & All & Male & Female & BW $<1500 \mathrm{~g}$ & Non-survivor \\
\hline \multicolumn{2}{l}{ Gastroschisis } & & & & \\
2009 & 61 & 36 & 25 & 6 & 3 \\
2010 & 69 & 36 & 33 & 3 & 2 \\
2011 & 63 & 28 & 34 & 5 & 3 \\
2012 & 55 & 29 & 26 & 2 & 3 \\
2013 & 68 & 37 & 30 & 5 & 1 \\
All & 316 & 166 & 148 & 21 & 12 \\
$\%$ & & $53 \%$ & $47 \%$ & $7 \%$ & $4 \%$ \\
Omphalocele & & & & \\
2009 & 34 & 14 & 20 & 3 & 4 \\
2010 & 42 & 28 & 14 & 0 & 7 \\
2011 & 42 & 24 & 17 & 5 & 8 \\
2012 & 46 & 25 & 20 & 4 & 6 \\
2013 & 33 & 20 & 11 & 3 & 7 \\
All & 197 & 111 & 82 & 15 & 32 \\
$\%$ & & $58 \%$ & $42 \%$ & $8 \%$ & $16 \%$ \\
\hline
\end{tabular}

$B W$ birth weight

found in 58 children, $17 \%$ of whom had birth weight below $1500 \mathrm{~g}$, in contrast to $4 \%$ with simple gastroschisis. The male:female ratio was opposite in complex gastroschisis, with a female predominance of $61 \%$. Intestinal problems that define complex gastroschisis were present in $7 \%$ of patients with omphalocele. Only one of these patients had birth weight below $1500 \mathrm{~g}$. The male:female ratio was $46: 54 \%$.

Urologic anomalies were more frequent in patients with omphalocele $(10 \% \mathrm{O}, 5 \% \mathrm{G})$, as were cardiac anomalies ( $32 \%$ O, 10\% G). Fifteen patients with omphalocele had trisomy 18 or 21 , and 12 had both trisomy and cardiac anomalies. Diaphragmatic hernia was present in $2 \%$ of the patients with omphalocele. Short bowel was coded for patients with gastroschisis only (5\%).

Mortality was $4 \%$ in the gastroschisis group (12 patients) and $16 \%$ in the omphalocele group (32 patients). Half of the non-survivors with gastroschisis and $44 \%$ of the non-survivors with omphalocele died during the first 10 days. Of the non-survivors with gastroschisis and omphalocele, $25 \%$ died after the third month of life. Survivors had a median length of stay at the first admission of 39 days (G) and 15 days (O) with ranges of 15-1069 days $(\mathrm{G})$ and 3-285 days $(\mathrm{O})$. The average initial hospital stay of patients with complex gastroschisis was 128.0 days (median 106). Readmissions were also more frequent in patients with complex gastroschisis and omphalocele than in those with simple gastroschisis. Of the survivors with gastroschisis, $61 \%$ had no readmission at the 3-month follow-up, and this decreased to $41 \%$ at the 12-month follow-up. Of those with omphalocele, 58\% had no readmission at the 3-month follow-up, and this also decreased to $41 \%$ at the 12 -month follow-up. The maximum 
Table 3 Distribution of related associated anomalies and relation to survival

\begin{tabular}{|c|c|c|c|c|}
\hline & \multicolumn{2}{|l|}{ Gastroschisis } & \multicolumn{2}{|l|}{ Omphalocele } \\
\hline & All (\%) & Non-survivors (\%) & All (\%) & Non-survivors (\%) \\
\hline Numbers & 316 & 12 & 198 & $32(16)$ \\
\hline Male & $166(53)$ & $4(33)$ & $111(58)$ & $10(31)$ \\
\hline Birth weight $<1500 \mathrm{~g}$ & $21(7)$ & $4(33)$ & $15(8)$ & $8(25)$ \\
\hline Intestinal problems ${ }^{\mathrm{a}}$ & $58(18)$ & $6(50)$ & $13(7)$ & $3(9)$ \\
\hline Atresia of small bowel & $35(11)$ & $3(25)$ & $6(3)$ & 0 \\
\hline Atresia of colon & $22(7)$ & $2(17)$ & $4(2)$ & $1(3)$ \\
\hline Volvulus & $8(3)$ & $2(17)$ & $1(1)$ & 0 \\
\hline Abnormal vascular supply of intestine & $13(4)$ & $3(25)$ & $3(2)$ & $2(6)$ \\
\hline Cardiac anomalies & $32(10)$ & 0 & $63(32)$ & $17(53)$ \\
\hline Lung hypoplasia & $1(<1)$ & $1(8)$ & $9(5)$ & $7(22)$ \\
\hline Diaphragmatic hernia & 0 & 0 & $4(2)$ & $2(6)$ \\
\hline Anomalies of urinary tract & $17(5)$ & 0 & $19(10)$ & $5(16)$ \\
\hline Anomalies of spine or thorax & 0 & 0 & $3(2)$ & $1(3)$ \\
\hline Trisomy 18 or 21 & 0 & 0 & $15(8)$ & $13(41)$ \\
\hline Procedures and follow-up & All (\%) & n.d.a. & All (\%) & n.d.a \\
\hline CAW & $235(74)$ & & $144(73)$ & \\
\hline Appendectomy & $43(14)$ & & $10(5)$ & \\
\hline Blood transfusion & $126(40)$ & & $68(34)$ & \\
\hline Gastrostomy & $5(2)$ & & $11(6)$ & \\
\hline Closure of ing. hernia & & & $11(6)$ & \\
\hline Short bowel & $16(5)$ & & & \\
\hline Survivors & Median (average) & IQR (range) & Median (average) & IQR (range) \\
\hline Length of initial stay & $39(61.0)$ & $28-69(15-1069)$ & 19 (41.6) & $11-35.5(3-285)$ \\
\hline Simple gastroschisis & $35(47.0)$ & $27-52.25(15-272)$ & & \\
\hline Complex gastroschisis & $105.5(128.0)$ & $47.75-149.75(18-1069)$ & & \\
\hline No. of readmissions & $1(1.2)$ & $0-2(0-11)$ & $0(1.4)$ & $0-2(0-9)$ \\
\hline Simple gastroschisis & $1(1.0)$ & $0-2(0-8)$ & & \\
\hline Complex gastroschisis & $2(2.3)$ & $1-3(0-11)$ & & \\
\hline
\end{tabular}

n.d.a. no data available, $C A W$ closure of abdominal wall without synthetic material, $I R Q$ interquartile range

${ }^{a}$ In gastroschisis correspondent with complex gastroschisis

number of readmissions during the first 12 months was 11 for patients with gastroschisis and 9 for patients with omphalocele.

Closure of the abdominal wall without synthetic material and without temporary closure could be performed in $74 \%$ of the patients with gastroschisis and $73 \%$ of those with omphalocele. In $43(\mathrm{G})$ versus $10(\mathrm{O})$ patients, appendectomy was performed. Five patients with gastroschisis and 11 with omphalocele required gastrostomy during the first 12 months, and $6 \%$ of the patients with omphalocele had closure of inguinal hernia during the first stay. Blood transfusion was required in $40 \%$ of the patients with gastroschisis and $34 \%$ of the patients with omphalocele.

The following variables were assessed for their impact on death from birth to 1 year later: sex, birth weight $<1500 \mathrm{~g}$, intestinal problems including atresia of the small bowel, atresia of the colon, volvulus and abnormal vascular supply to the intestine, cardiac anomalies, lung hypoplasia, anomalies of the urinary tract and trisomy 18 or 21 .

In both groups, birth weight below $1500 \mathrm{~g}$ was associated with significantly worse clinical outcome. The odds ratios $(95 \% \mathrm{CI})$ of patients with birth weight above $1500 \mathrm{~g}$ were 8.44 (2.09-29.80) and 7.52 (2.49-23.34) compared to patients with birth weight $\geq 1500 \mathrm{~g}$ in the gastroschisis group and in the omphalocele group, respectively (Figs. 1, 2).

In the gastroschisis group, intestinal problems had a negative effect on survival. This was significant for complex gastroschisis (odds ratio 4.85; 95\% CI 1.46-16.07), volvulus (odds ratio 9.93; 95\% CI 1.34-49.90) and abnormal blood supply of the intestine (odds ratio 9.80; 95\% CI 
Fig. 1 Gastroschisis: association with non-survival the first year of life. Forest plot shows the unadjusted odds ratio in base-10 log scale. Non-Surv non-survivors, $C I$ confidence interval, $P p$ value

$\begin{array}{lc}\text { Characteristics } & \text { Non-Surv/N } \\ \text { Sex } & \\ \text { Male } & 4 / 166 \\ \text { Female } & 6 / 148 \\ \text { Birth weight } & \\ \geq 1500 \mathrm{~g} & 8 / 295 \\ <1500 \mathrm{~g} & 4 / 21 \\ \text { Type of gastroschisis } & \\ \text { Simple } & 6 / 258 \\ \text { Complex } & 6 / 58 \\ \text { Atresia of small bowel } & \\ \text { No } & 9 / 281 \\ \text { Yes } & 3 / 35 \\ \text { Atresia of colon } & \\ \text { No } & 10 / 294 \\ \text { Yes } & 2 / 22 \\ \text { Volvulus } & \\ \text { No } & 10 / 308 \\ \text { Yes } & 2 / 8 \\ \text { Abnormal vascular supply intestine } \\ \text { No } \\ \text { Yes } & 9 / 303 \\ & 3 / 13\end{array}$

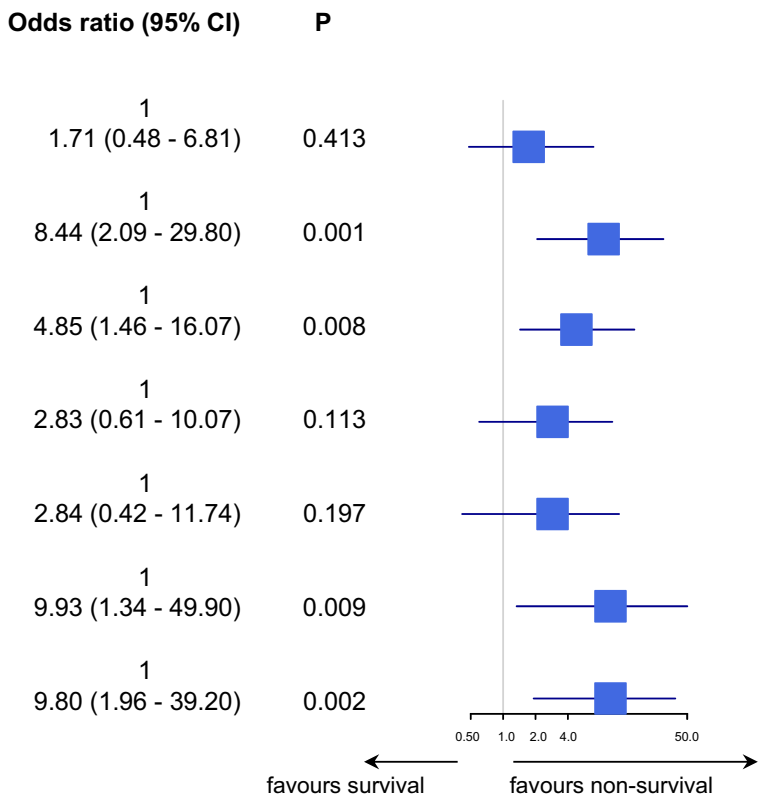

Fig. 2 Omphalocele: association with non-survival during the first year of life. The forest plot shows the unadjusted odds ratio on a base- $10 \log$ scale. Non-Surv non-survivors, $C I$ confidence interval, $P p$ value

\begin{tabular}{lr} 
Characteristics & Non-Surv/N \\
Sex & \\
Male & $10 / 111$ \\
Female & $18 / 82$ \\
Birth weight & \\
$\geq 1500 \mathrm{~g}$ & $24 / 182$ \\
$<1500 \mathrm{~g}$ & $8 / 15$ \\
Atresia of colon & \\
No & $31 / 193$ \\
Yes & $1 / 4$ \\
Abnormal vascular supply intestine \\
No & $30 / 194$ \\
Yes & $2 / 3$ \\
Cardiac anomalies & \\
No & $15 / 134$ \\
Yes & $17 / 63$ \\
Lung hypoplasia & \\
No & $25 / 188$ \\
Yes & $7 / 9$ \\
Diaphragmatic hernia & \\
No & $30 / 193$ \\
Yes & $2 / 4$ \\
Anomalies of urinary tract & \\
No & $27 / 178$ \\
Yes & $5 / 19$ \\
Anomalies of spine or thorax \\
No \\
Yes \\
Trisomy 18 or 21 \\
No \\
Yes & $31 / 194$ \\
\multicolumn{2}{l}{} \\
\end{tabular}

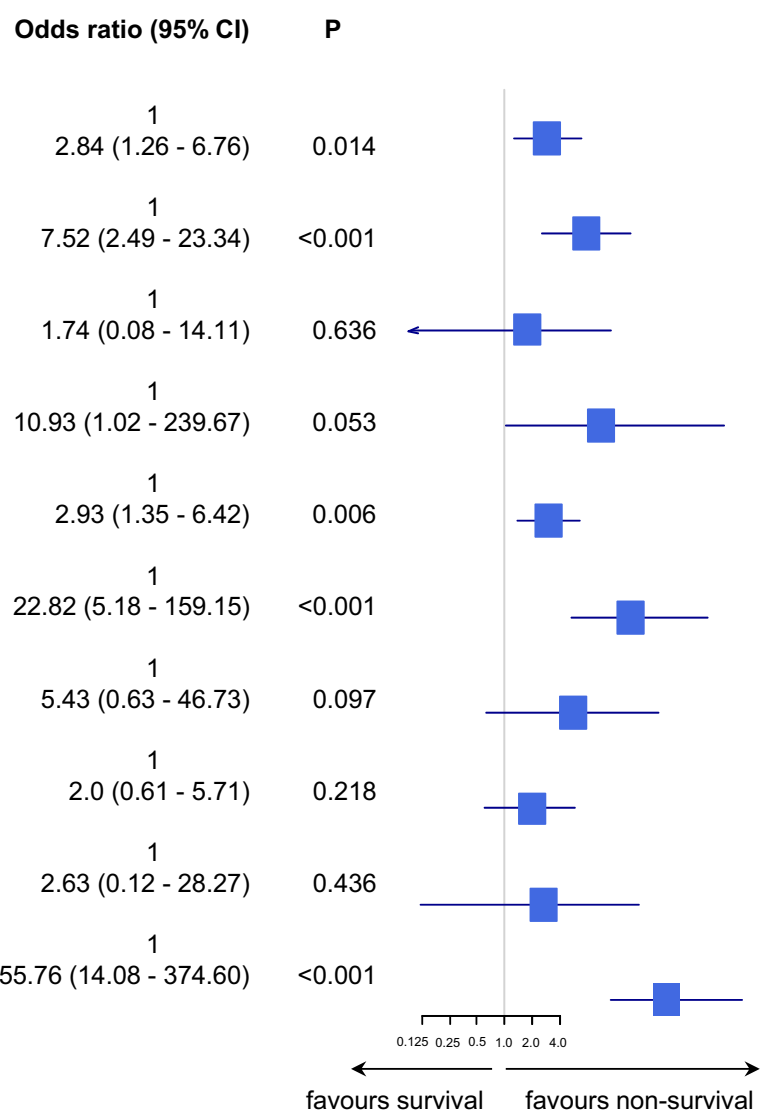

1.96-39.20) (Fig. 1). In the omphalocele group, female gender, lung hypoplasia and trisomy 18 and 21 had a significant negative impact on survival (Fig. 2). In the adjusted model, lung hypoplasia (odds ratio 24.22; $95 \%$ CI 3.55-227.93) and trisomy 18 and 21 (odds ratio 50.8;
95\% CI 8.70-469.28) remained significant, while cardiac anomalies lost significance (Fig. 3).

Figures 4 and 5 present the length of hospital stay for patients who were discharged home. In the gastroschisis group, no difference in the length of stay was found 
Fig. 3 Omphalocele: forest plot showing the adjusted odds ratio associated with non-survival in the first year of life on a base- 10 log scale. Non-Surv non-survivors, $C I$ confidence interval, $P$ $p$ value

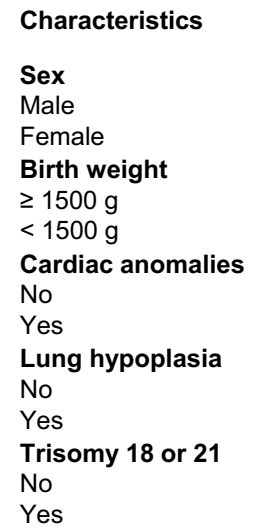

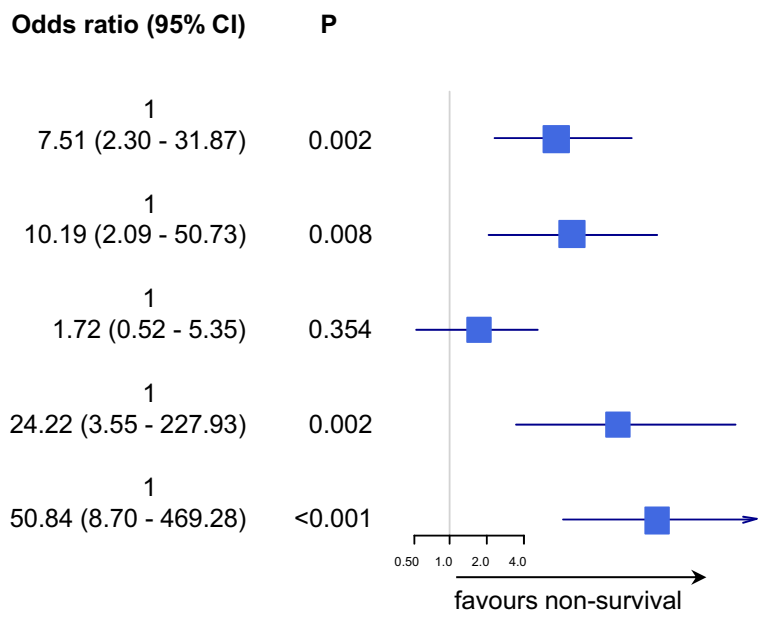

regarding sex, cardiac anomalies, volvulus and anomalies of the urinary tract. In contrast, birth weight, abnormalities of vascular supply of the intestine, atresia of the small bowel and atresia of the colon were associated with a significantly longer hospital stay. In the omphalocele group, patients with birth weight below $1500 \mathrm{~g}$ as well as cardiac anomalies and female patients showed a significantly longer hospital stay.

\section{Discussion}

Congenital anomalies are the second most prevalent cause of infant deaths in Germany [23]. Analysis of the medical care of patients with rare congenital anomalies is challenging in a country such as Germany, in which no nationwide clinical registry exists. Data that were originally collected for financial purposes have been shown to be a reliable resource for epidemiologic studies [11, 24, 25]. The strength of our study lies in the large cohort of approximately one-third of the German patients; this is the largest number of patients that has been analysed in a single study in Germany. But there are some differences regarding the population of persons insured by other statutory health insurance companies in terms of the age structure and comorbidity profile and the fact of a lower socioeconomic status of insured people at AOK [18].

As we used insurance claims data, there are some limitations in the study design. In Germany in 2003, the billing system for hospitals was changed to diagnosis-related groups (DRG). Hospitals receive a fixed income per treatment case based on the DRG of each case. For the assignment of DRG, patient-related data as ICD codes, age and procedures are used. Secondary diagnoses can lead to a better financed DRG, but not all do. The same applies to procedures. Together with the limitation on the number of secondary diagnoses to 20 per case, there might be an underestimation of associated anomalies that do not trigger a DRG.
We estimated the number of patients based on the birth statistics for Germany. The number of patients received from the AOK claims database was approximately 30\% lower for gastroschisis and $10 \%$ lower for omphalocele than the estimated number with incidence taken from existing literature $[1,2]$. This is due to the fact that the real incidence of gastroschisis and omphalocele is not known in Germany. There are only two regional registries for the epidemiology of congenital anomalies (Mainz and Saxony-Anhalt), covering about $3 \%$ of Germany. In these registries, the prevalence of gastroschisis was 3.06 per 10,000 livebirths, and the prevalence for omphalocele 0.69 per 10,000 livebirths for the years 2009-2013 [26]. With these data the estimated number of gastroschisis would nearly fit to our data $(6 \%$ lower than estimated), but not for omphalocele (156\% higher than estimated). Another reason that the prevalence of gastroschisis is lower than our estimation from literature is that gastroschisis is linked to low maternal age [27]. In Germany, the mean maternal age at first birth was 28.8 years in 2009 , and it increased to 29.3 years in 2013 [28]. Therefore, the prevalence of gastroschisis might be lower in Germany than in other countries with lower maternal age at pregnancy. The other cause of lower prevalence could be the termination rate. Gastroschisis and omphalocele are usually diagnosed prenatally [7]. In the Netherlands, an improved prenatal detection rate increased the pregnancy termination rate for abdominal wall defects [29]. A similar effect may apply to Germany, but no valid data on this are available.

Nevertheless, our data fit to other series described in the literature, as shown in Table 4. For both entities, we found male predominance, but male predominance is lower in gastroschisis than in omphalocele. The distribution of associated anomalies is consistent with that reported in the literature.

In gastroschisis, the predominant anomalies derive from the gastrointestinal tract. In our series, $18 \%$ of the cases could be classified as complex, showing intestinal atresia, 
A Overall cohort

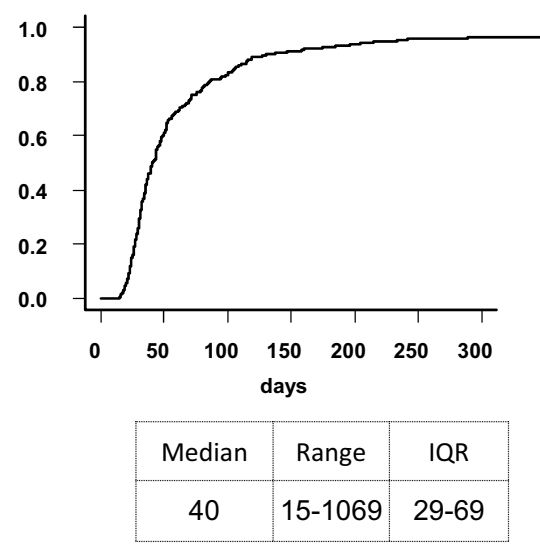

D Abnormal vascular supply intestine

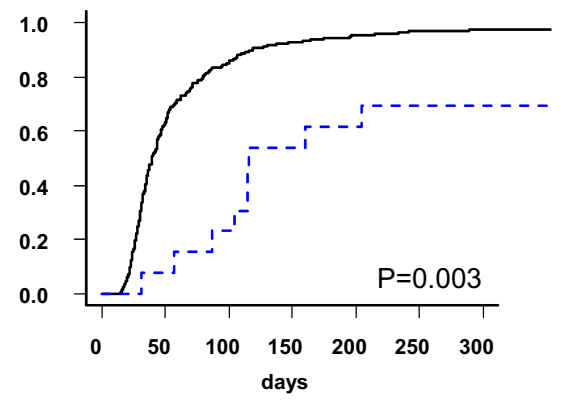

\begin{tabular}{|c|c|c|c|}
\hline & Median & Range & IQR \\
\hline$\underline{\text { No }}$ & 39 & $15-354$ & $29-39$ \\
\hline Yes & 116 & $31-1069$ & $91-149$ \\
\hline
\end{tabular}

G Atresia of colon

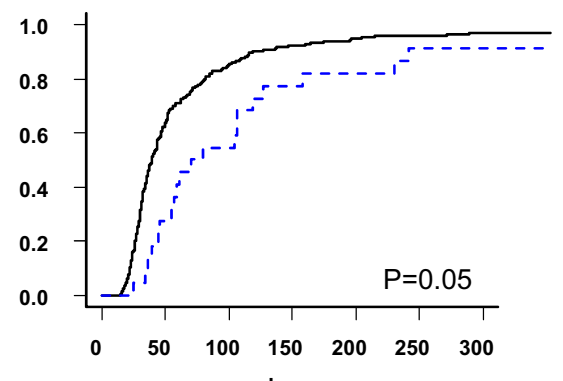

\begin{tabular}{|c|c|c|c|}
\hline & Median & Range & IQR \\
\hline$\underline{\text { No }}$ & 39 & $15-1069$ & $28-64$ \\
\hline Yes & 70 & $25-354$ & $46-119$ \\
\hline
\end{tabular}

B Sex

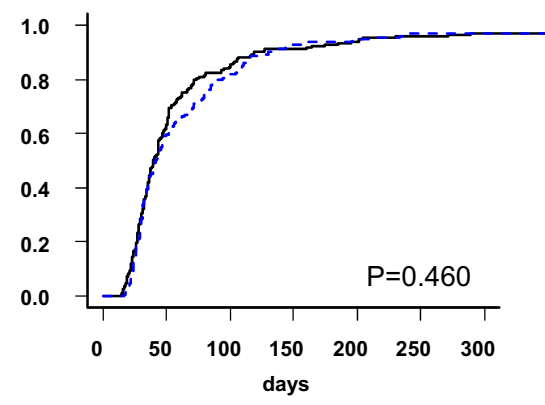

\begin{tabular}{|c|c|c|c|}
\hline & Median & Range & IQR \\
\hline Male & 40 & $15-1069$ & $29-69$ \\
\hline Female & 41 & $17-354$ & $30-79$ \\
\hline
\end{tabular}

E Volvulus

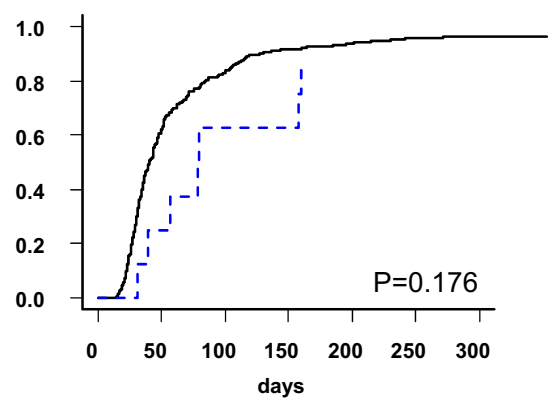

\begin{tabular}{|c|c|c|c|}
\hline & Median & Range & IQR \\
\hline$\underline{\text { No }}$ & 40 & $15-1069$ & $29-67$ \\
\hline Yes & 79 & $31-160$ & $48-119$ \\
\hline
\end{tabular}

H Cardiac anomalies

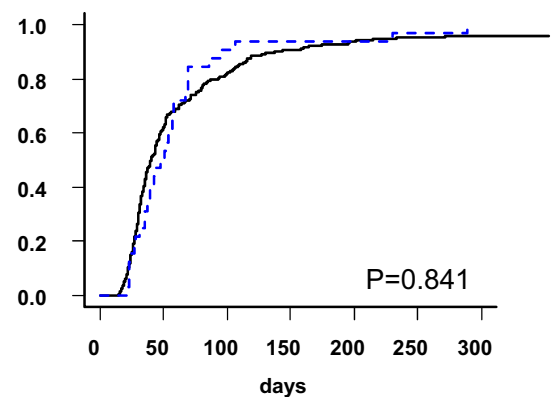

\begin{tabular}{|c|c|c|c|}
\hline & Median & Range & IQR \\
\hline$\underline{\text { No }}$ & 39 & $15-1069$ & $29-70$ \\
\hline Yes & 50 & $22-289$ & $34-68$ \\
\hline
\end{tabular}

C Birth weight

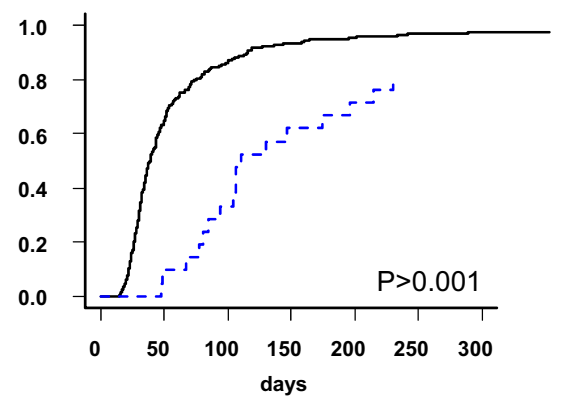

\begin{tabular}{|c|c|c|c|}
\hline & Median & Range & IQR \\
\hline$\geq 1500 \mathrm{~g}$ & 39 & $15-1069$ & $29-61$ \\
\hline$<1500 \mathrm{~g}$ & 110 & $48-230$ & $81-147$ \\
\hline
\end{tabular}

F Atresia of small bowel

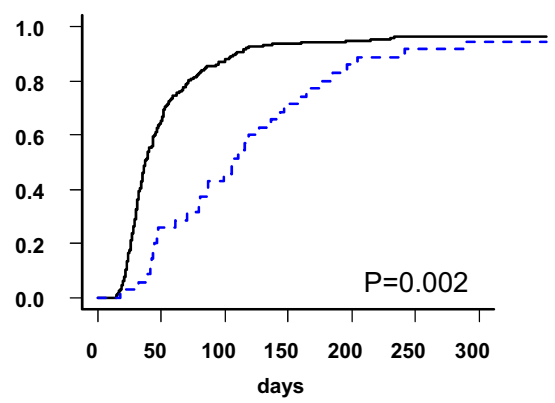

\begin{tabular}{|c|c|c|c|}
\hline & Median & Range & IQR \\
\hline$\underline{\text { No }}$ & 37 & $15-1069$ & $29-57$ \\
\hline Yes & 106 & $18-354$ & $51-155$ \\
\hline
\end{tabular}

\section{Anomalies of urinary tract}

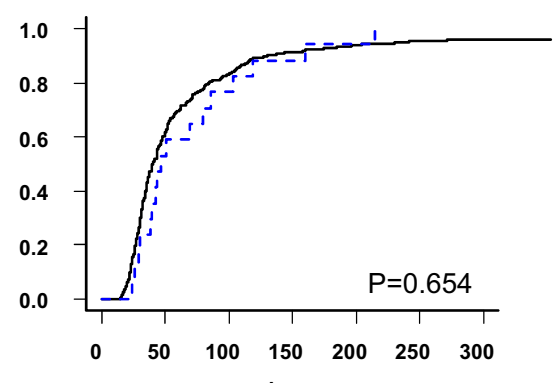

\begin{tabular}{|c|c|c|c|}
\hline & Median & Range & IQR \\
\hline$\underline{\text { No }}$ & 40 & $15-1069$ & $28-67$ \\
\hline Yes & 47 & $24-215$ & $38-86$ \\
\hline
\end{tabular}

Fig. 4 Gastroschisis. Cumulative incidence curves for hospital discharge. The curves do not reach $100 \%$ because fatalities before discharge were considered competing risks 
A Overall cohort

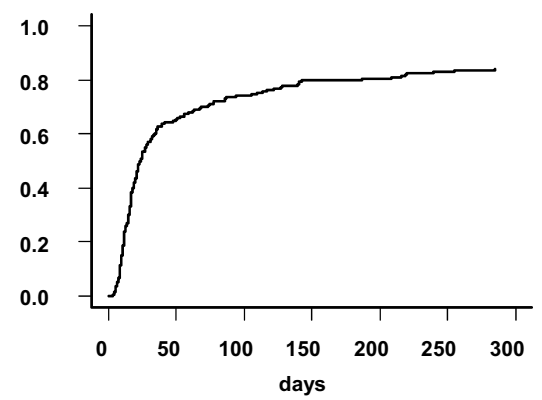

\begin{tabular}{|c|c|c|}
\hline Median & Range & IQR \\
\hline 23 & $3-285$ & $12-39$ \\
\hline
\end{tabular}

D Cardiac anomalies

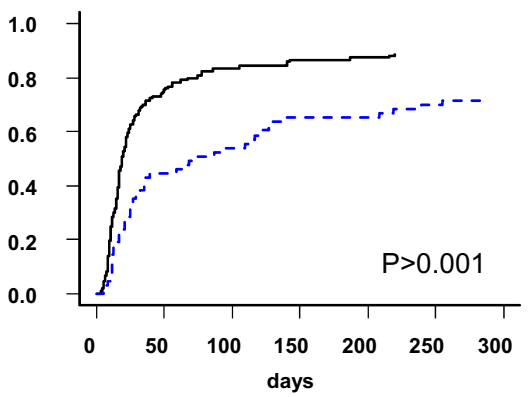

\begin{tabular}{|c|c|c|c|}
\hline & Median & Range & IQR \\
\hline No & 19 & $3-285$ & $11-36$ \\
\hline Yes & 70 & $22-187$ & $39-122$ \\
\hline
\end{tabular}

B Sex

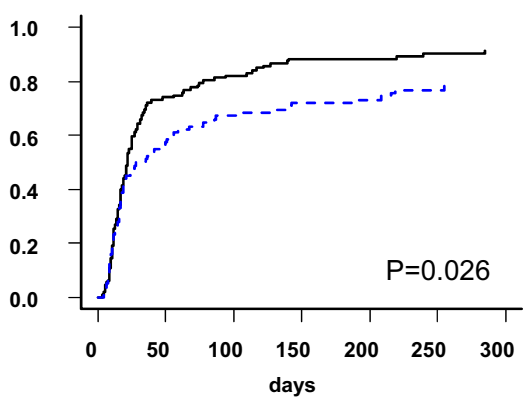

\begin{tabular}{|c|c|c|c|}
\hline & Median & Range & IQR \\
\hline Male & 21 & $3-285$ & $12-33$ \\
\hline Female & 30 & $4-255$ & $11-56$ \\
\hline
\end{tabular}

E Lung hypoplasia

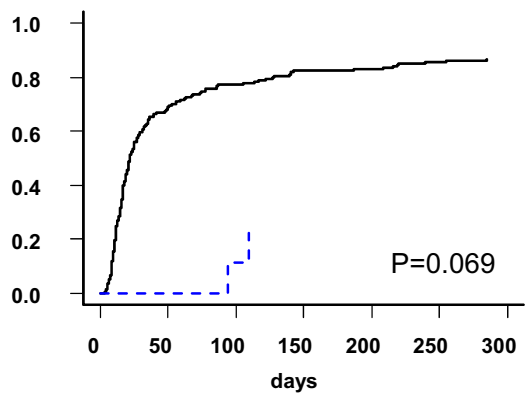

\begin{tabular}{|c|c|c|c|}
\hline & Median & Range & IQR \\
\hline No & 40 & $3-285$ & $12-36$ \\
\hline Yes & & $94-110$ & $98-106$ \\
\hline
\end{tabular}

C Birth weight

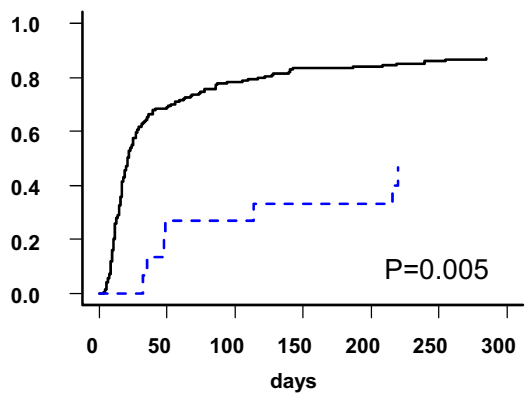

\begin{tabular}{|c|c|c|c|}
\hline & Median & Range & IQR \\
\hline$\geq 1500 \mathrm{~g}$ & 21 & $3-285$ & $11-35$ \\
\hline$<1500 \mathrm{~g}$ & & $32-220$ & $42-162$ \\
\hline
\end{tabular}

F Atresia of urinary tract

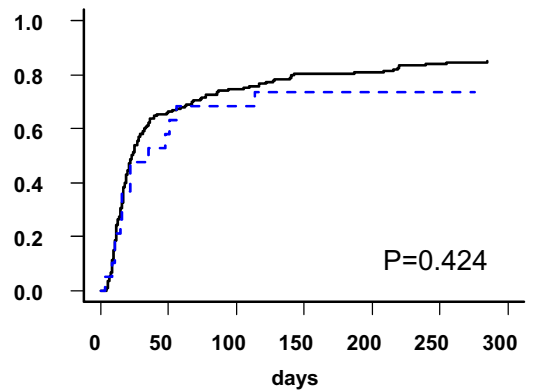

\begin{tabular}{|c|c|c|c|}
\hline & Median & Range & IQR \\
\hline No & 23 & $4-285$ & $12-38$ \\
\hline Yes & 35 & $3-114$ & $11-45$ \\
\hline
\end{tabular}

Fig. 5 Omphalocele. Cumulative incidence curves for hospital discharge. The curves do not reach $100 \%$ because fatalities before discharge were considered competing risks. It was not possible to cal-

Table 4 Comparison of our data with literature

\begin{tabular}{lllllc}
\hline & \multicolumn{2}{l}{ Gastroschisis } & & \multicolumn{2}{l}{ Omphalocele } \\
\cline { 2 - 3 } \cline { 5 - 6 } \cline { 5 - 6 } & Our data & literature $^{\mathrm{a}}$ & & Our data & literature $^{\mathrm{a}}$ \\
\hline Male (\%) & 53 & $52-54$ & 58 & $51-59$ \\
$<1500 \mathrm{~g}(\%)$ & 7 & $0.1-5.6$ & 8 & $6-8$ \\
Cardiac (\%) & 10 & $1-15$ & 32 & $11-56$ \\
Pulmonary (\%) & $<1$ & $<1-5$ & 5 & $2-8$ \\
Gastrointestinal (\%) & 18 & $5-15$ & & $7-15$ \\
Urologic (\%) & 5 & $1-15$ & 10 & $6-17$ \\
Genetic (\%) & 0 & $0.1-1.7$ & 8 & $15-32$ \\
Length of stay (median) & 39 & $25-45$ & & 15 & $15-23$ \\
Mortality (\%) & 4 & $1,4-6,5$ & 16 & $16-19$
\end{tabular}

a $[24,30,31,34-41]$ culate a median for omphalocele patients with lung hypoplasia, and trisomy 18 and 21 because $78 \%$ and $87 \%$ of the patients died before discharge

volvulus or anomalies of vascular supply of the intestine; this is consistent with a previously reported series [30,31]. The incidences of colonic atresia and small bowel atresia are almost equal, which is fits to the series of Fleet and Shah [32, 33]. We found cardiac anomalies in one-third of the patients with omphalocele. The incidence of genetic anomalies was lower than that reported in the literature, and this might be due to prenatal counselling and termination of pregnancies.

In our group, gastroschisis has a low mortality rate of $4 \%$. This is slightly higher than the best rates reported in the literature, but we also found a higher rate of children with birth weight under $1500 \mathrm{~g}$, a condition that has a negative impact on survival. In other studies, these children were not counted [41]. Consistent with the literature, we confirmed 
that complex gastroschisis has an impact on the outcome, resulting in longer hospital stay and higher mortality [40]. The rate of short bowel syndrome in gastroschisis is 5\%, almost the same as Raymond found for a larger series in the USA (6\%) [40]. The outcome in patients with omphalocele is mainly determined by the presence of trisomy, low birth weight or lung hypoplasia. Mortality in patients with omphalocele is four times as high as in patients with gastroschisis. This is also consistent with other series. In both groups, intestinal atresia alone had no significant impact on survival. The longer hospitalization of patients with gastroschisis than of those with omphalocele has been shown in other series as well [34]. The reason for this cannot be determined based on our data, because the data do not contain information on the course of enteral feeding as one of the possible reasons for delayed discharge. Further research based on clinical data is needed here.

The debate regarding centralization of paediatric surgery is an ongoing discussion. Between 2009 and 2013, about 110 paediatric surgical units were registered in Germany [10]. Due to data protection requirements, our study does not reveal information on the centres, which treated abdominal wall defects. In an earlier study, we showed that paediatric surgery is organized in a decentralized way in Germany for legislative and historical reasons. This effect is homogeneous for our country. In that study, only one unit had performed more than 15 procedures for closure of abdominal wall defects [10]. For this reason, we took Germany as an example for low-volume (1-4 cases per year) and mediumvolume (5-13 cases per year) hospitals according to the classification of Dubrovsky [35].

Based on our data, we showed that the outcome of gastroschisis and omphalocele is equal to the outcome reported in international series. Therefore, we conclude that there is no negative volume effect on mortality, similar to the recent conclusions of Dubrovsky and Hong [35, 41].

\section{Conclusion}

Despite the fact that paediatric surgical care is organized in a decentralized manner in Germany, the mortality rates for gastroschisis and omphalocele are equal to those reported in international data.

Acknowledgements Open Access funding provided by Projekt DEAL. We are grateful to the "Wissenschaftliches Institut der AOK" (WIdO) for the provision of statutory health insurance (SHI) claims data.

Author contributions All authors contributed to the study conception and design. The first draft of the manuscript was written by AS and all authors commented on previous versions of the manuscript. All authors read and approved the final manuscript.
Funding There was no funding of the study.

\section{Compliance with ethical standards}

Conflict of interest All authors declare that they have no potential conflict of interest.

Ethical approval This article does not contain any studies with human participants or animals performed by any of the authors.

Open Access This article is licensed under a Creative Commons Attribution 4.0 International License, which permits use, sharing, adaptation, distribution and reproduction in any medium or format, as long as you give appropriate credit to the original author(s) and the source, provide a link to the Creative Commons licence, and indicate if changes were made. The images or other third party material in this article are included in the article's Creative Commons licence, unless indicated otherwise in a credit line to the material. If material is not included in the article's Creative Commons licence and your intended use is not permitted by statutory regulation or exceeds the permitted use, you will need to obtain permission directly from the copyright holder. To view a copy of this licence, visit http://creativecommons.org/licenses/by/4.0/.

\section{References}

1. Benjamin B, Wilson GN (2014) Anomalies associated with gastroschisis and omphalocele: analysis of 2825 cases from the Texas Birth Defects Registry. J Pediatr Surg 49:514-519. https://doi. org/10.1016/j.jpedsurg.2013.11.052

2. Springett A, Draper ES, Rankin J, Rounding C, Tucker D, Stoianova S, Wellesley D, Morris JK (2014) Birth prevalence and survival of exomphalos in England and wales: 2005 to 2011. Birth Defects Res A Clin Mol Teratol 100:721-725. https://doi. org/10.1002/bdra.23301

3. Frolov P, Alali J, Klein MD (2010) Clinical risk factors for gastroschisis and omphalocele in humans: a review of the literature. Pediatr Surg Int 26:1135-1148. https://doi.org/10.1007/s00383-010-2701-7

4. Christison-Lagay ER, Kelleher CM, Langer JC (2011) Neonatal abdominal wall defects. Semin Fetal Neonatal Med 16:164-172. https://doi.org/10.1016/j.siny.2011.02.003

5. Arnold MA, Chang DC, Nabaweesi R, Colombani PM, Bathurst MA, Mon KS, Hosmane S, Abdullah F (2007) Risk stratification of 4344 patients with gastroschisis into simple and complex categories. J Pediatr Surg 42:1520-1525. https://doi.org/10.1016/j.jpedsurg.2007.04.032

6. Garne E, Loane M et al (2005) Prenatal diagnosis of severe structural congenital malformations in Europe. Ultrasound Obstet Gynecol 25:6-11. https://doi.org/10.1002/uog.1784

7. Prefumo F, Izzi C (2014) Fetal abdominal wall defects. Best Pract Res Clin Obstet Gynaecol 28:391-402. https://doi.org/10.1016/j. bpobgyn.2013.10.003

8. (2017) GBA: The Federal Joint Committee Richtlinie des Gemeinsamen Bundesausschusses über Maßnahmen zur Qualitätssicherung der Versorgung von Früh- und Reifgeborenen gemäß§ 136Absatz 1Nummer2 SGBVinVerbindung mit § 92 Abs.1 Satz2Nr. 13 SGBV. https://www.g-ba.de/downloads/62-492-1386/ QFR-RL_2017-02-16_iK-2017-05-03.pdf. Accessed 30 Sep 2019

9. Bauer J, Groneberg DA, Maier W, Manek R, Louwen F, Brüggmann D (2017) Accessibility of general and specialized obstetric care providers in Germany and England: an analysis of location and neonatal outcome. Int J Health Geogr 16:44. https://doi. org/10.1186/s12942-017-0116-6 
10. Schmedding A, Rolle U (2017) Decentralized rather than centralized pediatric surgery care in Germany. Eur J Pediatr Surg 27:399-406. https://doi.org/10.1055/s-0037-1607026

11. Dingemann C, Dietrich J, Zeidler J, Blaser J, Gosemann JH, Lacher M, Ure B (2017) Surgical management of congenital abdominal wall defects in Germany: a population-based study and comparison with literature reports. Eur J Pediatr Surg 27:516-525. https://doi.org/10.1055/s-0037-1598250

12. German Institute of Medical Documentation and Information International statistical classification of diseases and related health problems, 10th revision, German modification. https:// www.dimdi.de/dynamic/en/classifications/icd/icd-10-gm/index .html. Accessed 30 Sep 2019

13. German Institute of Medical Documentation and Information German procedure classification (Operationen- und Prozedurenschlüssel-OPS). https://www.dimdi.de/dynamic/en/classifica tions/ops/. Accessed 30 Sep 2019

14. National Association of Statutory Health Insurance Funds (GKVSpitzenverband) (2019) Annex to convention according to $\S 301$ Abs. 3 SGB V (Technischen Anlagen der Vereinbarung nach § 301 Abs. 3 SGB V). https://www.gkv-datenaustausch.de/leistungserbrin ger/krankenhaeuser/krankenhaeuser.jsp. Accessed 30 Sep 2019

15. Federal Statistical Office Current updating of population figures 12411-0001 population: Germany, reference date. https://wwwgenesis.destatis.de/genesis/online/data. Accessed 30 Sep 2019

16. Federal Ministry of Health: Mitglieder und Versicherte der Gesetzlichen Krankenversicherung (GKV). https://www.bundesgesu ndheitsministerium.de/themen/krankenversicherung/zahlen-undfakten-zur-krankenversicherung/mitglieder-und-versicherte.html. Accessed 30 Sep 2019

17. (2016) Statistisches Bundesamt: Sozialleistungen Angaben zur Krankenversicherung (Ergebnisse des Mikrozensus). Fachserie 13 Reihe 1.1. https://www.vgsd.de/wp-content/uploads/2016/10/Krank enversicherung_Mikrozensus_2011.pdf. Accessed 30 Sep 2019

18. Hoffmann F, Icks A (2012) Structural differences between health insurance funds and their impact on health services research: results from the Bertelsmann health-care monitor. Gesundheitswesen 74:291-297. https://doi.org/10.1055/s-0031-1275711

19. Federal Statistical Office Birth statistics. 12612-0001 live births: Germany, years, sex. https://www-genesis.destatis.de/genesis/ online/data. Accessed 30 Sep 2019

20. Fine JP, Gray RJ (1999) A proportional hazards model for the subdistribution of a competing risk. J Am Stat Assoc 94:496-509. https://doi.org/10.1080/01621459.1999.10474144

21. Brock GN, Barne C, Ramirez JA, Myers J (2011) How to handle mortality when investigating length of hospital stay and time to clinical stability. BMC Med Res Methodol 11:144. https://doi. org/10.1186/1471-2288-11-144

22. R-Core-Team (2017) The R foundation for statistical computing c/o Institut für Statistik und Wahrscheinlichkeitstheorie der Technischen Universität Wien: R, a language and environment for statistical computing and graphics (Version 3.3.3), University of Vienna, Austria

23. Federal Statistical Office Causes of death statistics: 23211-0003 deaths: Germany, years, causes of death, age groups. https://wwwgenesis.destatis.de/genesis/online/data. Accessed 30 Sep 2019

24. Youssef F, Cheong LH, Emil S, Canadian Pediatric Surgery Network (CAPSNet) (2016) Gastroschisis outcomes in North America: a comparison of Canada and the United States. J Pediatr Surg 51:891-895. https://doi.org/10.1016/j.jpedsurg.2016.02.046

25. Abdullah F, Arnold MA, Nabaweesi R, Fischer AC, Colombani PM, Anderson KD, Lau H, Chang DC (2007) Gastroschisis in the United States 1988-2003: analysis and risk categorization of 4344 patients. J Perinatol 27:50-55. https://doi.org/10.1038/sj.jp.7211616

26. European network of population-based registries for the epidemiological surveillance of congenital anomalies. https://eu-rd-platf orm.jrc.ec.europa.eu/eurocat/eurocat-data/prevalence. Accessed 10 Dec 2019

27. Siega-Riz AM, Herring AH, Olshan AF, Smith J, Moore C, National Birth Defects Prevention Study (2009) The joint effects of maternal prepregnancy body mass index and age on the risk of gastroschisis. Paediatr Perinat Epidemiol 23:51-57. https://doi. org/10.1111/j.1365-3016.2008.00990.x

28. Institute for Work, Skills and Training (2018) Durchschnittsalter der Frauen bei der Geburt des ersten Kindes. https://www. sozialpolitik-aktuell.de/tl_files/sozialpolitik-aktuell/_Politikfel der/Bevoelkerung/Datensammlung/PDF-Dateien/abbVII4.pdf. Accessed 30 Sep 2019

29. Fleurke-Rozema H, van de Kamp K, Bakker M, Pajkrt E, Bilardo C, Snijders R (2017) Prevalence, timing of diagnosis and pregnancy outcome of abdominal wall defects after the introduction of a national prenatal screening program. Prenat Diagn 37:383-388. https://doi.org/10.1002/pd.5023

30. Gonzalez DO, Cooper JN, St Peter SD, Minneci PC, Deans KJ (2018) Variability in outcomes after gastroschisis closure across U.S. children's hospitals. J Pediatr Surg 53:513-520. https://doi. org/10.1016/j.jpedsurg.2017.04.012

31. Song YK, Nunez Lopez O, Mehta HB, Bohanon FJ, Rojas-Khalil Y, Bowen-Jallow KA, Radhakrishnan RS (2017) Race and outcomes in gastroschisis repair: a nationwide analysis. J Pediatr Surg 52:1755-1759. https://doi.org/10.1016/j.jpedsurg.2017.03.004

32. Fleet MS, de la Hunt MN (2000) Intestinal atresia with gastroschisis: a selective approach to management. J Pediatr Surg 35:13231325. https://doi.org/10.1053/jpsu.2000.9324

33. Shah R, Woolley MM (1991) Gastroschisis and intestinal atresia. J Pediatr Surg 26:788-790. https://doi.org/10.1016/00223468(91)90139-k

34. Corey KM, Hornik CP, Laughon MM, McHutchison K, Clark RH, Smith PB (2014) Frequency of anomalies and hospital outcomes in infants with gastroschisis and omphalocele. Early Hum Dev 90:421-424. https://doi.org/10.1016/j.earlhumdev.2014.05.006

35. Dubrovsky G, Sacks GD, Friedlander S, Lee S (2017) Understanding the relationship between hospital volume and patient outcomes for infants with gastroschisis. J Pediatr Surg 52:1977-1980. https ://doi.org/10.1016/j.jpedsurg.2017.08.065

36. Kong JY, Yeo KT, Abdel-Latif ME et al (2016) Outcomes of infants with abdominal wall defects over 18 years. J Pediatr Surg 51:1644-1649. https://doi.org/10.1016/j.jpedsurg.2016.06.003

37. Lamoshi A, Rothstein DH (2019) Risk factors for inpatient mortality in patients born with gastroschisis in the United States. Am J Perinatol. https://doi.org/10.1055/s-0039-1694732

38. Lao OB, Larison C, Garrison MM, Waldhausen JH, Goldin AB (2010) Outcomes in neonates with gastroschisis in U.S. children's hospitals. Am J Perinatol 27:97-101. https://doi. org/10.1055/s-0029-1241729

39. Raymond SL, Downard CD, St Peter SD, Baerg J, Qureshi FG, Bruch SW, Danielson PD, Renaud E, Islam S (2019) Outcomes in omphalocele correlate with size of defect. J Pediatr Surg 54:15461550. https://doi.org/10.1016/j.jpedsurg.2018.10.047

40. Raymond SL, Hawkins RB, St Peter SD, Downard CD, Qureshi FG, Renaud E, Danielson PD, Islam S (2019) Predicting morbidity and mortality in neonates born with gastroschisis. J Surg Res 245:217-224. https://doi.org/10.1016/j.jss.2019.07.065

41. Hong CR, Fullerton BS, Han SM, Morrow KA, Edwards EM, Soll RF, Jaksic T, Horbar JD, Modi BP (2019) Impact of disease-specific volume and hospital transfer on outcomes in gastroschisis. J Pediatr Surg 54:65-69. https://doi.org/10.1016/j.jpeds urg.2018.10.034

Publisher's Note Springer Nature remains neutral with regard to jurisdictional claims in published maps and institutional affiliations. 